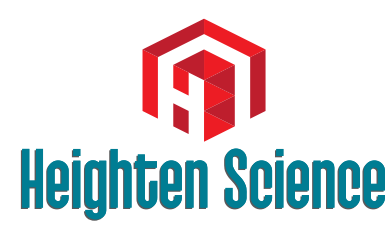

P U B L I C A T I O N S Corporation

Review Article

\title{
A Review on filaricidal activity of phytochemical extracts against filariasis and the Parasites Genomic Diversity
}

\author{
AM Gumel ${ }^{1 *}$ and MM Dogara ${ }^{2}$ \\ 'Department of Microbiology and Biotechnology, Faculty of Science, Federal University Dutse, \\ PMB. 7156, Dutse, Jigawa State, Nigeria \\ ${ }^{2}$ Department of Biological Sciences, Faculty of Science, Federal University Dutse, PMB.7156, \\ Dutse, Jigawa State, Nigeria
}

\begin{abstract}
*Address for Correspondence: Dr. AM Gumel, Department of Plant Science and Biotechnology, Faculty of Science, Federal University Dutse 7156, Dutse, Jigawa State, Nigeria, Email: dr.gumel@fud.edu.ng
\end{abstract}

Submitted: 15 October 2018

Approved: 25 October 2018

Published: 26 October 2018

Copyright: (๑) 2018 Gumel AM, et al. This is an open access article distributed under the Creative Commons Attribution License, which permits unrestricted use, distribution, and reproduction in any medium, provided the original work is properly cited

Keywords: Molecular biology; Filariasis; Elephantiasis; Parasitology; Phytochemicals

Check for updates

\section{Abstract}

Filariasis is one of the Neglected Tropical Diseases (NTDs) known to be of serious public health importance and pose devastating socio-economic burden especially among the poor people in tropical and subtropical countries of the world. The parasite is responsible for lymphatic filariasis affecting about 1.3 billion people in 72 countries worldwide. The major parasitic agents of the infection are three closely related nematodes of clade Onchocercidae namely Wuchereria bancrofti, Brugia malayi and $B$. timori that are transmitted to human through bites by mosquitoes of genera: Aedes, Anopheles, Culex and Mansonia. The disease is targeted by the World Health Organization (WHO) for elimination by 2020 through the use of chemically synthesized drugs used as therapeutic agents to cure the disease but there are some setbacks. Phytochemical extracts are viewed as alternative therapy in the management of the disease. Additionally, the species have many ecological variants and are diversified in terms of their genetic fingerprint. This diversification in terms of genomic sequences as well as rapid infection rate warrant the lymphatic filarial parasites to respond differently to diagnostic and therapeutic interventions. Thus understanding the genomic diversity of the parasite will help in efficient therapeutic management of the disease, thereby eliminating it to prevent unnecessary suffering and contribute to the reduction of poverty. In this review, we have highlighted on the used for phytochemical extracts in the therapeutic management of the lymphatic and the molecular genetic diversity of the parasite was delineated.

\section{Introduction}

Lymphatic filariasis is a vector-borne infection with parasitic nematodes of family Filariodidea namely: Wuchereria bancrofti, Brugia malayi and B. timori. About $90 \%$ of the infection is reported to be caused by Wuchereria bancrofti and the remainder is due to infection with either B. malayi or B. timori [1]. The parasites are transmitted via mosquito bites [2,3]. Lymphatic filariasis is transmitted by different types of mosquitoe genera, for example, in urban and semi-urban areas the disease is transmitted by Culex mosquito, which is widespread across such habitat. In rural areas, the disease is said to be transmitted by Anopheles, while Aedes, mainly in endemic islands in the Pacific 1].

Adult worms lodge in the lymphatic vessels and disrupt the normal function of the lymphatic system. The worms can live for approximately 6 - 8 years and, during their life time, produce millions of microfilariae (immature larvae) that circulate in the blood. The death of the filarial parasite causes inflammation within the host which initiates the first step of its pathogenesis. Infections are mainly hidden and often acquired during childhood leading to a lifetime of an impaired lymphatic system, suppressing the host immunity and increased risk of debilitating episodes filarial fever known as 
adenolymphangitis (ADL). The host inflammation resulted in an altered lymphatic system and the abnormal enlargement of body parts e.g. lymphoedema, hydrocoele, and elephantiasis thus resulting in chronic disabling consequences of the damage caused by infections of the lymphatic vessels. This causes acute and chronic morbidity in humans within tropical and subtropical areas of Africa, Asia, the Western Pacific, and some parts of the Americas resulting in high public health and socio-economic burden within the affected societies [4].

According to World Health Organization (WHO) fact sheets, more than 1.3 billion people in 72 countries worldwide are threatened by lymphatic filariasis, with 856 million people in 52 countries living in areas that require preventive chemotherapy to stop the spread of infection [1]. The global baseline estimate of people affected by lymphatic filariasis was 25 million men with hydrocele and over 15 million people with lymphoedema and elephantiasis. At least 36 million people remain with these chronic disease manifestations.

Several chemotherapeutic drugs (albendazole, ivermectin, diethylcarbamazine citrate) are employed in the management of filariasis. Interestingly, the drug is said to be effective even when used as monotherapy [2]. Unfortunately, most of these synthetic drugs are characterized with adverse side effects warranting the recent surge of research on alternative therapeutic drugs.

Phytochemical extracts are reported to have potential bioactivity against lymphatic filariasis [5-10]. Among them are those obtained from Andrographis paniculata [11], Azadirachta indica [12], Haliclona oculata [13] Polyalthiasu aveolens [14]. This article highlighted a review on recent literatures that reported the efficacy of some phytochmical extracts against filarial parasites. It also explores the genetic diversity that exists within different strains of the filarial parasites. It is believed that understanding the genomic diversity of the parasite will help in efficient therapeutic management of the disease, thereby eliminating it to prevent unnecessary suffering and contribute to the reduction of poverty.

\section{Phyto-chemicals extracts used as filaricidal agents}

Ricinus communis (Family: Euphorbiaceae): The plant is commonly known as castor oil plant found in both the tropical and temperate climates of the world. Literature has documented that $R$. communis seeds extracts posses bioactivity against warts, cold tumours, been widely used as a human laxative-cathartic agent [15]. The filaricidal effect of organic solvent extract of $R$. communis seeds against filarial parasite B. malayi at varying dosage was reported [15]. The research indicates dose dependent filaricidal activity (40-90\%). In contrast, Nisha et al. [16] reported that treatment with ethanol fraction $(1 \mathrm{mg} / \mathrm{ml})$ of $R$. communis seed extract caused a complete suppression of $S$. digitata microfilarial growth within $1 \mathrm{hr}, 40 \mathrm{~min}$. In fact, Nisha et al. [16], established that using the extract, incur $72.39 \%$ microfilarial growth inhibition [16].

Haliclona oculata (Family: Chalinidae): The demospongie (Haliclona oculata) a marine of family Chalinidae is known to possess a variety of bioactivity against several diseases such as cancer [17], neurodegeneration [18], type-2 diabetes [19], fungal and microbial infections [20,21]. The bioactivity of these sponges is thought to be due to possession of novel sterols, metabolites including steroids, terpenoids, alkaloids, cyclic peptides and unsaturated fatty acids [13]. Gupta et al. (2012) reported that administering methanolic extract, of $H$. oculata at $100 \mathrm{mg} / \mathrm{kg}$ for five consecutive days by sub-cutaneous route demonstrated significant macrofilaricidal efficacy of $51.3 \%, 64 \%$ and $70.7 \%$, respectively. Chemical analyses of the extract revealed that it contained a mixture of four alkaloids (Figure 1) namely mimosamycin, xestospongin-C, xestospongin-D and araguspongin- $C$ together with few minor compounds [13]. This observation was found to be in resonance with Lakshmi et al. [22], on anti-filarial activity of another species, $H$. exigua against lymphatic B. malayi. In vitro and in vivo 




Figure 1: Alkaloids extracts of Haliclona spp.

study showed that $31.25 \mu \mathrm{g} / \mathrm{ml}$ concentrations of the crude alcoholic extract soluble fractions were able to kill the adult worms. Whereas the chloroform extract was found to be effective at lower concentration $(15.6 \mu \mathrm{g} / \mathrm{ml})$, and the observed bioactivity was attributed due to the presence of araguspongin-C.

Azadirachta indica (Family: Meliaceae): Popularly called as 'Neem tree', the plant is a large evergreen tree with its height reaching up to $50 \mathrm{ft}$. [23]. It is widely distributed within the hot tropical regions especially in India and West Africa [24]. The leaves and bark of this tree has a bitter taste of triterpenoid azadirachtin [25]. Almost every part of this tree is reported to be used in complementary medicine for the cure of different ailments such as anti-microbial [26], anti-inflammatory [27], anti-cancer [28], antimalarial [29], anti-ulcerogenic [30] and anti-filarial [23] activities. Al-Rofaai et al. [12] reported the effect of $A$. indica leaf extract against helminthes Teladorsagia circumcincta. Employing organic solvents extraction and aqueous fractionation methods, they found that the first stage larvae $\left(\mathrm{L}_{1}\right)$ were shown to be more sensitive having the lowest $\mathrm{LC}_{50}$ at $7.15 \mathrm{mg} / \mathrm{ml}$ of the extract as compared to $24.91 \mathrm{mg} / \mathrm{ml}$ on infective stage larvae $\left(\mathrm{L}_{3}\right)$. Other workers employing distilled alcoholic and aqueous extracts of $A$. indica flowers showed that it has potential anti-filarial activity against microfilariae of Setariacervi [23]. The study also showed that the inhibition was concentration dependent, and both extracts were found to have almost similar lethal effect on the microfilariae of $S$. cervi, with $\mathrm{LC}_{50}$ being 15 and $18 \mathrm{ng} / \mathrm{ml}$, respectively [23].

Adrographis paniculata Linn (Family: Acanthaceae): Andrographispaniculata (Green Chiretta) is an annual herbaceous plant belonging to the family Acanthaceae, native to Southeast Asian. It has been traditionally used for centuries in Ayurvedic medicine. The herb has been revered for treating infectious diseases and highly regarded as having a preventative effect for many diseases, due to its powerful immune strengthening benefits [31]. Extensive research literatures has revealed that $A$. paniculata has a broad range of pharmacological activities in different ailments such as anti-analgesic [32], anti-oxidant [33], anti-biofilm [34], gastro-protective [35], wound healing [36], hepatoprotective [37], anti-filarial [11], anti-cancer [38], anti-malarial [39] and anti-termites [40]. It has been reported that the prophylactic effect of Andrographis was able to stop the catastrophic effect of the deadly flu virus of 1919 global epidemic from reaching India [41]. In fact, its bioactive diterpenoid andrographolide and its analogs were reported to block the MCF-7 breast cancer cells cycle at the G0-G1 phase [42].

Kumarappan et al. [43] studied the anti-filarial activity of alcoholic extract of $A$. paniculata, the study reported that aqueous extract of the leaves showed microfilaricidal activity on Dipetalonema reconditum within $40 \mathrm{~min}$, both in vitro and in vivo. Administration of the extract $(0.06 \mathrm{ml} / \mathrm{Kg}$ body weight $)$ reduced the number of the microfilariae in infected dogs by more than $85 \%$ (Dutta \& Sukul, 1982). Earlier, Zaridah et al. [44] reported the filaricidal activity of $A$. paniculata aqueous leaf extract against B.malayi. The authors analyzed the anti-filarial activity of the extract using relative movability (RM) value of the adult worm over a period of 24 hrs resulting in the total death of the parasite when treated with 5 or $10 \mathrm{mg} / \mathrm{ml}$ of the extract. 
Hibiscus species (Family: Malvaceae): H. sabdariffa (roselle) is a native of tropics, used for the production of fiber and infusions that are normally used as beverages. It is a woody shrub of annual to perennial seasoning. It is reported to have several medicinal efficacies especially on hypertensive patients [45]. The plants is said to be rich in anthocyanins, as well as dihydroxybenzoic acid. Daphniphylline forms the major pigment, while the dried calyces contain the flavonoids gossypetin, hibiscetine and sabdaretine. In addition, a small amount of delphinidin-3-monoglucoside, cyaniding3-monoglucoside, and delphinidin were also present [45]. Moreover, the seeds were reported to be a good source of lipid-soluble antioxidants, particularly gammatocopherol [46]. Recently, ethanolic extract of $H$. sabdariffa leafs were reported to exhibit filaricidal activity against B. malayi (Saxena et al., 2011). The efficacy of the plant extract filaricidal activity was assessed using both the in vivo and in vitro motility and MTT reduction assays on the microfilariae (mf) and adult worms. The authors found that administering the leaf-extract at $500 \mathrm{mg} / \mathrm{ml}$ for 5 days, incurred about $30 \%$ macrofilaricidal efficacy and $42 \%$ sterilization of female worms in Meriones unguiculatus. On the other hand, feeding $M$. coucha with the extract $(1 \mathrm{~g} / \mathrm{kg}$, for 5 days) exerted $57 \%$ macrofilaricidal with $64 \%$ sterilizing effect on female worms (Saxena et al., 2011). In a similar studies, the crude methanolic extract of $H$. mutabilis (confederate rose) and the isolated bioactive molecule 'ferulic acid' were tested against bovine S. cervi [47]. The authors reported that both the extract and the bioactive molecule 'ferulic acid' exerted significant filaricidal activities against $S$. cervi [47].

Cardiospermum halicacabum (Family: Sapindaceae): Cardiospermum halicacabum (balloon vine), is a climbing plant (Figure 2) widely distributed in tropical and subtropical regions of Africa and Asia [48]. This plant has been reported to have bioactivity such as homoeopathic [48] and anti-diarrheal efficacy [49], anti-microbial [50,51]. The filaricidal activity of ethanolic and aqueous extracts of $C$. halicacabum against B. pahangi was previously reported is [52]. The researchers found activity on adult worms and the amount of microfilarial released by female worms was concentration and time dependent. For example, using $500 \mu \mathrm{g} / \mathrm{ml}$, the authors observed the aqueous extract to significantly reduce motility of adult females after $24 \mathrm{~h}$ of exposure, the release of microfilariae from female worms on day 2 and the motility of the adult males after 3 days. However, the aqueous extract at this concentration $(500 \mu \mathrm{g} / \mathrm{ml})$ did not affect the motility of microfilariae with the exception of those in higher concentration extracts. In contrast, 500 $\mu \mathrm{g} / \mathrm{ml}$ of the ethanol extract was found to rapidly reduce the motility of microfilariae on day 2. Furthermore, higher concentrations of ethanol extracts $(2 \mathrm{mg} / \mathrm{ml})$ inhibit both the motility of adult worms and the release of microfilariae from females [52].

\section{Molecular diversity of the parasite}

Currently, WHO has launched a massive campaign on the global program to eliminate lymphatic filariasis (GPELF), through elimination of its causative agents: $W$. bancrofti, B. malayi, and B. timori (Figure 3), through a combination of mass drug administration

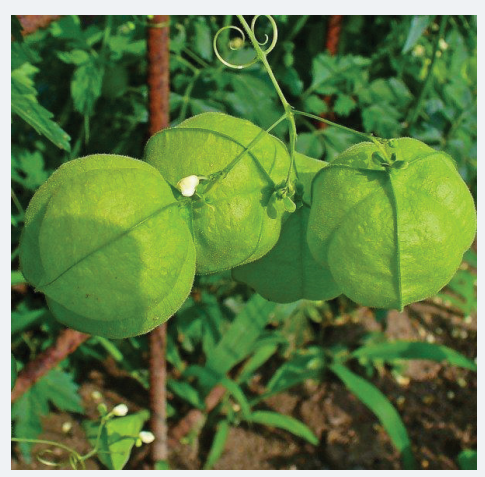

Figure 2: Cardiospermum halicacabum 


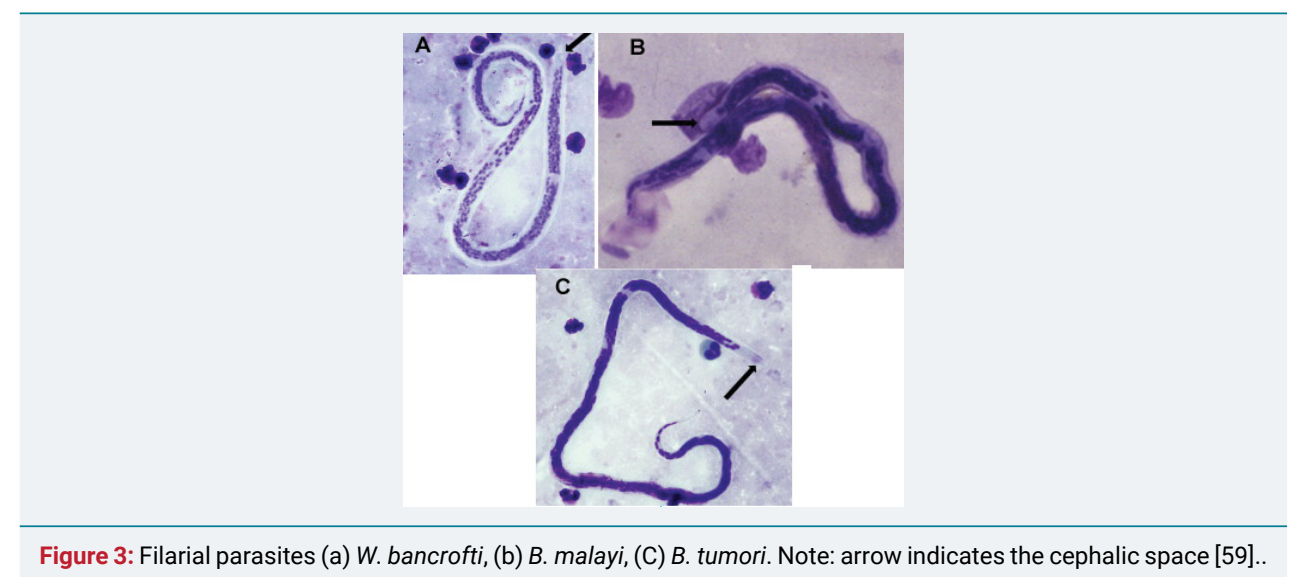

Figure 3: Filarial parasites (a) W. bancrofti, (b) B. malayi, (C) B. tumori. Note: arrow indicates the cephalic space [59].

(MDA) and integrated vector management (IVM) [53]. The current goal of GPELF is to eliminate lymphatic filariasis by the year 2020. Despite constituting a major public health problem posed by lymphatic filariasis in many tropical and subtropical regions, the parasites' genetics and genomics remains poorly understood [54].

Current tools available to monitor LF are limited to diagnostic tests targeting DNA repeats, filarial antigens, and anti-filarial antibodies. While these tools are useful for detection and surveillance, unfortunately, elimination programs have yet to take full advantage of molecular typing for inferring infection history, strain fingerprinting, and evolution.

To this end, molecular genetics have proved to be a valuable tool in deciphering the evolutionary history of parasites as well as improving the knowledge of infectious disease epidemiology [53]. Genetic analysis provides a glimpse into the epidemic history of a parasite that can complement epidemiological analysis or even in some cases replacing missing surveillance data. With the advent of polymorphic molecular markers for the filarial parasites especially bacnroftian filaria, it is now possible to apply population genetic analysis to understand lymphatic filariasis.

Molecular typing approaches have included whole mitochondrial genomes, genotyping, targeted sequencing, and random amplified polymorphic DNA (RAPDs) in order to systematically delineate different species variants of the parasites. For example, mitochondrial (mt) genome sequences have enabled comparison of population genetics and evolution for numerous free-living and parasitic nematodes. Ramesh et al. [54] have compared the complete mt genome of $W$. bancrofti through analysis of isolates from Papua New Guinea, India and West Africa. Using mt genome sequence for B. malayi as a reference, the researchers were able to assemble the sequences for each isolate and annotate it. The study described that the length of the $W$. bancrofti mt genome is approximately 13,637 nucleotides, it also contains 2 ribosomal RNAs (Figure 4), 22 transfer RNAs, 12 protein-coding genes, and is characterized by a $74.6 \%$ AT content [54]. It further asserts that the $W$. bancrofti mt gene order is identical to that reported for Onchocerca volvulus, Dirofilaria immitis, Setaria digitata and B. malayi [54].

Papua New Guinea researchers identified 5 major strains that were widespread and many minor strains some of which exhibit geographic stratification. Genome data, while rare, has been utilized to reconstruct evolutionary relationships among taxa of the filarial Onchocercidae and identify gene synteny. Their phylogeny reveals that speciation from the common ancestor of both B. malayi and $W$. bancrofti occurred around 5-6 million years ago with shared ancestry to other filarial nematodes as recent as 15 million years ago.

Previous study had employed the use of comparison of random amplified polymorphic DNA (RAPD) and amplified fragment length polymorphism (AFLP) 
profiles to identify robust molecular markers for bancroftian parasite of Indian variant [55]. Using RAPD marker (OP8) primer after digestion with $\lambda$ DNA/HindIII and ФX174/ HaeIII, the researchers were able to reveal variations between the parasite populations (Figure 5) collected from different regions [55].

In contrast to the above studies, Ghedin et al. [56] have sequenced 90 megabase pairs genome of B. malayi and inferred that the parasite has between 14,500 and 17,800 protein-coding genes [57], have reviewed the comparative genomics of nematodes. The review highlighted that analysis of conserved synteny between B. malayi and C. elegans revealed a preponderance of within-chromosome linkage, but little local synteny $[57,58]$. B. malayi has five chromosome pairs, and comparisons of genes linked in $B$. malayi against $C$. elegans suggest that the changed chromosome number is the result of a fusion between genomic segments corresponding to C. elegans chromosomes I and III. However, since the related filarioid of Setaria is reported as having $n=6$ [57], the fusion could have occurred in the onchocercine lineage.
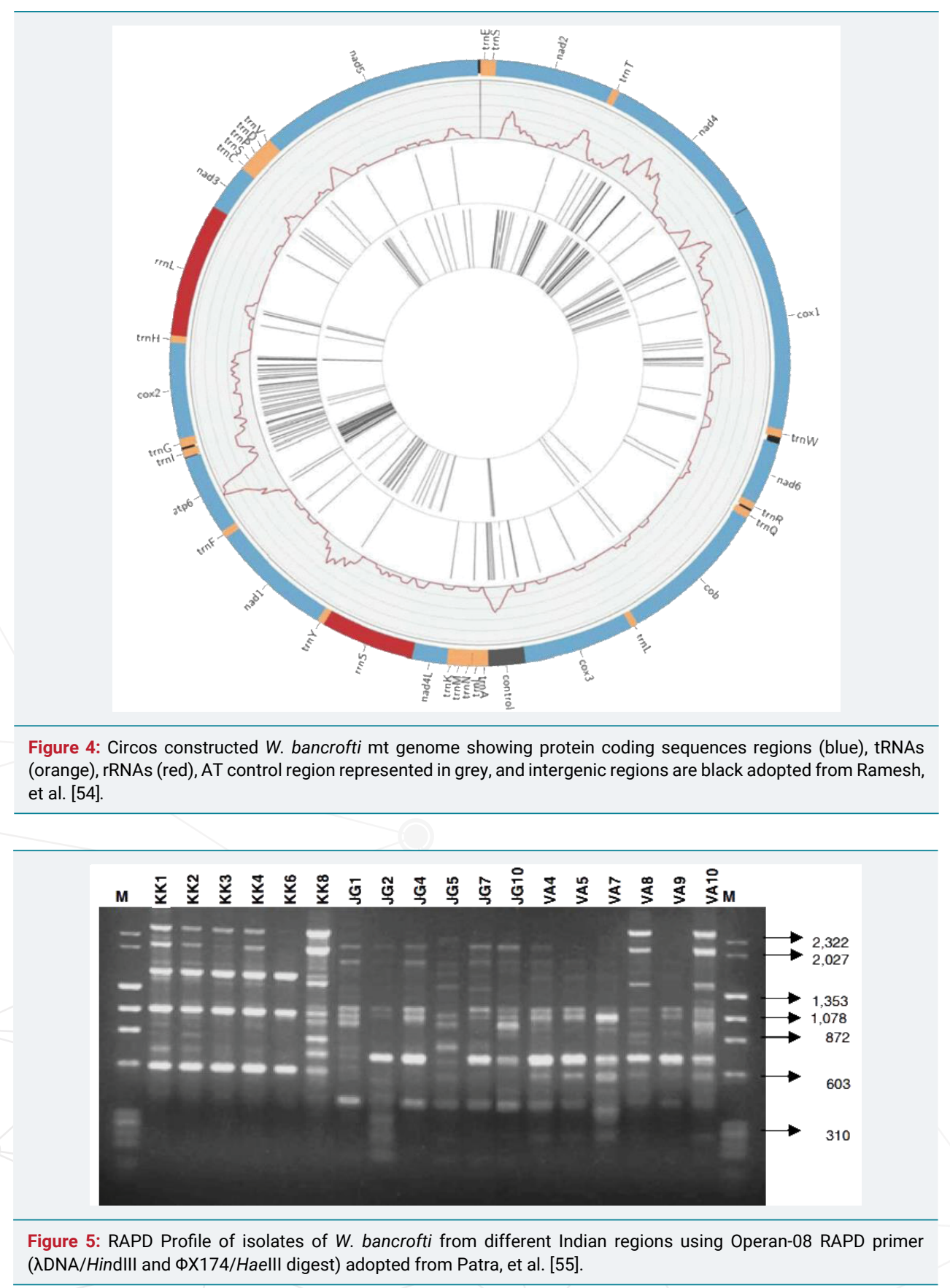


\section{Conclusion}

Lymphatic filariasis affects about 1.3 billion people in 72 countries worldwide. The major parasitic agents of the infection are three closely related nematodes of clade Onchocercidae namely Wuchereria bancrofti, Brugia malayi and B. timori. Chemically synthesized drugs are known to be used as therapeutic agents to manage the disease but with some setbacks such as carcinogenic impurities and adverse side effects. Thus prompting the current observed challenges encountered in its therapeutic management. Phytochemical extracts on the other hand, have proved to be effective against the filarial parasites. Again, the parasites species have many ecological variants that are almost similar to one another and to related taxa. We believe that understanding the genomic diversity of the parasite will help in efficient therapeutic management of the disease, thereby eliminating it to prevent unnecessary suffering and contribute to the reduction of poverty.

\section{References}

1. WHO. (2018). Lymphatic Filariasis. Fact Sheets. 2018; Ref.: https://goo.gl/TY6eCn

2. Questions T, East M, Room R. The Lancet Seminar: Lymphatic filariasis and onchocerciasis. The Lancet. 2010; 376: 1175-1185. Ref.: https://goo.gl/ZKmE13

3. WHO. Lymphatic filariasis Fact Sheet: World Health Organisation. 2012.

4. Bockarie MJ, Pedersen EM, White GB, Michael E. Role of vector control in the global program to eliminate lymphatic filariasis. Annu Rev Entomol. 2009; 54: 469-487. Ref.: https://goo.gl/ZVaAZg

5. Katiki LM, Ferreira JFS, Gonzalez JM, Zajac AM, Lindsay DS, et al. Anthelmintic effect of plant extracts containing condensed and hydrolyzable tannins on Caenorhabditis elegans, and their antioxidant capacity. Vet Parasitol. 2013; 192: 218-227. Ref.: https://goo.gl/Wi6py4

6. Kumar N, Misra P, Dube A, Bhattacharya S, Dikshit M, et al. Piper betle Linn. a maligned Pan-Asiatic plant with an array of pharmacological activities and prospects for drug discovery. Current Science. 2010; 99: 922-932. Ref.: https://goo.gl/aeCePa

7. Patra JK, Dhal NK, Thatoi HN. In vitro bioactivity and phytochemical screening of Suaeda maritima (Dumort): A mangrove associate from Bhitarkanika, India. Asian Pac J Trop Med. 2011; 4: 727-734. Ref.: https://goo.gl/vkE5aK

8. Saxena K, Dube V, Kushwaha V, Gupta V, Lakshmi M, et al. Antifilarial efficacy of Hibiscus sabdariffa on lymphatic filarial parasite Brugia malayi. Medicinal Chemistry Research, 2011; 20: 1594-1602. Ref.: https://goo.gl/NA7NKu

9. Yadav D, Singh SC, Verma RK, Saxena K, Verma R, et al. Antifilarial diarylheptanoids from Alnus nepalensis leaves growing in high altitude areas of Uttarakhand, India. Phytomedicine. 2013; 20: 124-132. Ref.: https://goo.gl/1ozRQ1

10. Zaman MA, lqbal Z, Abbas RZ, Khan MN, Muhammad G, et al. In vitro and in vivo acaricidal activity of a herbal extract. Vet Parasitol. 2012; 186: 431-436. Ref.: https://goo.gl/bdM3E1

11. Sheeja BD, Sindhu D, Ebanasar J, Jeeva S. Larvicidal activity of Andrographis paniculata (Burm.f) Nees against Culex quinquefasciatus Say (Insecta: Diptera-Culicidae), a filarial vector. Asian Pacific Journal of Tropical Disease. 2012; 2: S574-S578. Ref.: https://goo.gl/ji8F47

12. Al-Rofaai A, Rahman WA, Sulaiman SF, Yahaya ZS. In vitro activity of neem (Azadirachta indica) and cassava (Manihot esculenta) on three pre-parasitic stages of susceptible and resistant strains of Teladorsagia (Ostertagia) circumcincta. Vet Parasitol. 2012; 188: 85-92. Ref.: https://goo.gl/Xvy3Xt

13. Gupta J, Misra S, Mishra SK, Srivastava S, Srivastava MN, et al. Antifilarial activity of marine sponge Haliclona oculata against experimental Brugia malayi infection. Exp Parasitol. 2012; 130: 449-455. Ref.: https://goo.gl/xH2jqq

14. Ngantchou I, Nyasse B, Denier C, Blonski C, Hannaert V, et al. Antitrypanosomal alkaloids from Polyalthia suaveolens (Annonaceae): Their effects on three selected glycolytic enzymes of Trypanosoma brucei. Bioorg Med Chem Lett. 2010; 20: 3495-3498. Ref.: https://goo.gl/vgT6KK

15. Ramanathan T, Shanmugapriya R. Antifilarial activity of seed extracts of Ricinus communis against Brugia malayi. J Pharmacy Res. 2012; 5. Ref.: https://goo.gl/gFnG8w

16. Nisha $M$, Kalyanasundaram $M$, Paily K, Vanamail $P$, Balaraman $K$. In vitro screening of medicinal plant extracts for macrofilaricidal activity. Parasitol Res. 2007; 100: 575-579. Ref.: https://goo.gl/ZeSbhk 
17. Coello L, Martín MJ, Reyes F. 1, 5-diazacyclohenicosane, a new cytotoxic metabolite from the marine sponge Mycale sp. Mar Drugs. 2009; 7: 445-450.

18. Rao KV, Donia MS, Peng J, Garcia-Palomero E, Alonso D, et al. Manzamine B and E and ircinal A related alkaloids from an Indonesian Acanthostrongylophora sponge and their activity against infectious, tropical parasitic, and Alzheimer's diseases. J Nat Prod. 2006; 69: 1034-1040. Ref.: https://goo.gl/21a9u8

19. Orhan I, Şener B, Kaiser M, Brun R, Tasdemir D. Inhibitory activity of marine sponge-derived natural products against parasitic protozoa. Mar Drugs. 2010; 8: 47-58. Ref.: https://goo.gl/kQ2cxp

20. Lipton A. Antifungal and Cytotoxic Activities of Some Marine Sponges Collected from the South East Coast of India. Journal of Applied Pharmaceutical Science. 2012; 2: 52-55. Ref.: https://goo.gl/SvHyHG

21. Rajendran I, Sobhana K, Annie Selva Sonia G, Chakraborty K, Vijayan K, et al. Antibacterial and antifungal properties of southeast Indian coastal sponges. J Marine Biological Association of India. 2011; 53: 272-274. Ref.: https://goo.gl/fo8fTp

22. Lakshmi V, Srivastava S, Kumar Mishra S, Misra S, Verma M, et al. In vitro and in vivo antifilarial potential of marine sponge, Haliclona exigua (Kirkpatrick), against human lymphatic filarial parasite Brugia malayi. Parasitol Res. 2009; 105: 1295-1301. Ref.: https://goo.gl/5sNKVV

23. Mishra V, Parveen N, Singhal KC, Khan NU. Antifilarial activity of Azadirachta indica on cattle filarial parasite Setaria cervi. Fitoterapia. 2005; 76: 54-61. Ref.: https://goo.gl/r3JQHY

24. Koh HL, Chua TK, Tan CH. A guide to medicinal plants: an illustrated, scientific and medicinal approach: World Scientific Publishing Company Incorporated. 2009. Ref.: https://goo.gl/VGjemf

25. Veitch GE, Beckmann E, Burke BJ, Boyer A, Maslen SL, et al. Synthesis of Azadirachtin: A Long but Successful Journey. Angew Chem Int Ed Engl. 2007; 46: 7629-7632. Ref.: https://goo.gl/LXHW31

26. Tripathi A, Chandrasekaran N, Raichur A, Mukherjee A. Antibacterial applications of silver nanoparticles synthesized by aqueous extract of Azadirachta indica (Neem) leaves. J Biomed Nanotechnol. 2009; 5: 93-98. Ref.: https://goo.gl/b6R6Jo

27. Schumacher M, Cerella C, Reuter S, Dicato M, Diederich M. Anti-inflammatory, pro-apoptotic, and antiproliferative effects of a methanolic neem (Azadirachta indica) leaf extract are mediated via modulation of the nuclear factor-kB pathway. Genes Nutr. 2011; 6: 149-160. Ref.: https://goo.gl/DqnDXE

28. Othman F, Motalleb G, Peng SLT, Rahmat A, Fakurazi S, et al. Extract of Azadirachta indica (Neem) Leaf Induces Apoptosis in 4T1 Breast Cancer BALB/c Mice. Cell J. 2011; 13: 107-116. Ref.: https://goo.gl/TGCLEK

29. Lucantoni L, Yerbanga RS, Lupidi G, Pasqualini L, Esposito F, et al. Transmission blocking activity of a standardized neem (Azadirachta indica) seed extract on the rodent malaria parasite Plasmodium berghei in its vector Anopheles stephensi. Malar J. 2010; 9: 66. Ref.: https://goo.gl/Nxd8gx

30. Aziz Q. To Study The Anti-ulcer Effect Of Azadirachta Indica Leaf Extract And Isolated Compound Of Neemnimolicine (nc) In Comparison With Ulcer Healing Drugs On Gastric Mucosa Of Albino Rats. Baqai Medical University, Karachi. 2011.

31. Chandrasekaran C, Thiyagarajan P, Sundarajan K, Goudar KS, Deepak M, et al. Evaluation of the genotoxic potential and acute oral toxicity of standardized extract of Andrographis paniculata $\left(K\right.$ (almCold ${ }^{\mathrm{TM}}$ ). Food Chem Toxicol. 2009; 47: 1892-1902. Ref.: https://goo.gl/w57iVZ

32. Shivaprakash G, Gopalakrishna H, Padbidri DS, Sadanand S, Sekhar SS, et al. Evaluation of Andrographis paniculata leaves extract for analgesic activity. J Pharmacy Research. 2011; 4: 33753377.

33. Qader SW, Abdulla MA, Chua LS, Najim N, Zain MM, et al. Antioxidant, total phenolic content and cytotoxicity evaluation of selected Malaysian plants. Molecules. 2011; 16: 3433-3443. Ref.: https://goo.gl/4qb6XS

34. Murugan K, Selvanayaki K, Al-Sohaibani S. Antibiofilm activity of Andrographis paniculata against cystic fibrosis clinical isolate Pseudomonas aeruginosa. World Journal of Microbiology and Biotechnology, 2011; 27: 1661-1668. Ref.: https://goo.gl/NZ44qq

35. Wasman S, Mahmood A, Suan Chua L, Alshawsh MA, Hamdan S. Antioxidant and gastroprotective activities of Andrographis paniculata (Hempedu Bumi) in Sprague Dawley rats. Indian J Exp Biol. 2011; 49: 767. Ref.: https://goo.gl/zyZdjX

36. Al-Bayaty FH, Abdulla MA, Hassan MIA, Ali HM. Effect of Andrographis paniculata leaf extract on wound healing in rats. Nat Prod Res. 2012; 26: 423-429. Ref.: https://goo.gl/NaQs9V

37. Chao WW, Lin BF. Hepatoprotective Diterpenoids Isolated from Andrographis paniculata. Chinese Medicine. 2012; 3: 136-143. Ref.: https://goo.gl/Ai7nnq 
38. Ajaya Kumar R, Sridevi K, Vijaya Kumar N, Nanduri S, Rajagopal S. Anticancer and immunostimulatory compounds from Andrographis paniculata. Journal of ethnopharmacology, 2004; 92: 291-295. Ref.: https://goo.gl/RzL8uW

39. Govindarajan M. Evaluation of Andrographis paniculata Burm.f. (Family:Acanthaceae) extracts against Culex quinquefasciatus (Say.) and Aedes aegypti (Linn.) (Diptera:Culicidae). Asian Pac J Trop Med. 2011; 4: 176-181. Ref.: https://goo.gl/xazR2y

40. Elango G, Abdul Rahuman A, Kamaraj C, Bagavan A, Abduz Zahir A, et al. Efficacy of medicinal plant extracts against Formosan subterranean termite, Coptotermes formosanus. Industrial Crops and Products. 2012; 36: 524-530. Ref.: https://goo.gl/jk3PmN

41. Shipard I. King of Bitters (Andrographis paniculata). 2009.

42. Satyanarayana C, Deevi D, Rajagopalan R, Srinivas N, Rajagopal S. DRF 3188 a novel semi-synthetic analog of andrographolide: cellular response to MCF 7 breast cancer cells. BMC Cancer. 2004; 4: 26 Ref.: https://goo.gl/Qmd5AF

43. Kumarappan C, Senthil S, Sundari SKK, Jaswanth A. Anti-filarial activity of some valuable Indian medicinal plants. Asian Journal of Experimental Sciences, 2009; 23: 553-558.

44. Zaridah M, Idid S, Wan Omar A, Khozirah S. In vitro antifilarial effects of three plant species against adult worms of subperiodic Brugia malayi. J Ethnopharmacol. 2001; 78: 79-84. Ref.: https://goo.gl/jK5H3m

45. Ali BH, Wabel NA, Blunden G. Phytochemical, pharmacological and toxicological aspects of Hibiscus sabdariffa L.: a review. Phytother Res. 2005; 19: 369-375. Ref.: https://goo.gl/DVLu1x

46. Mohamed R, Fernandez J, Pineda M, Aguilar M. Roselle (Hibiscus sabdariffa) Seed Oil Is a Rich Source of $\mathrm{Y}$-Tocopherol. J Food Sci. 2007; 72: S207-S211. Ref.: https://goo.gl/Q8XonL

47. Saini $P$, Gayen $P$, Nayak A, Kumar D, Mukherjee N, et al. Effect of ferulic acid from Hibiscus mutabilis on filarial parasite Setaria cervi: Molecular and biochemical approaches. Parasitol Int. 2012; 61520 531. Ref.: https://goo.gl/HyWaz5

48. EMEA. Committee for veterinary medicibnal product Cardiospermum halicacabum: The European agency for the evaluation of medicinal products. 1999.

49. Prakash K, Rao N, Shanta Kumar S. Pharmacological investigation of Cardiospermum halicacabum (Linn) in different animal models of diarrhea. 2006; 38. Ref.: https://goo.gl/sbEVRB

50. Deepan T, Alekhya V, Saravanakumar P, Dhanaraju M. Phytochemical and Anti-Microbial Studies on the Leaves Extracts of Cardiospermum halicacabum Linn. Advances in Biological Research. 2012; 6 : 14-18. Ref.: https://goo.gl/BJGK2n

51. Shareef H, Rizwani GH, Mahmood S, Khursheed R, Zahid H. In vitro antimicrobial and phytochemiccal analysis of Cardiospermum halicacabum L. Pak J Bot. 2012; 44: 1677-1680. Ref.: https://goo.gl/7v2nMi

52. Khunkitti W, Fujimaki Y, Aoki Y. In vitro antifilarial activity of extracts of the medicinal plant Cardiospermum halicacabum against Brugia pahangi. J Helminthol. 2000; 74: 241-246. Ref.: https://goo.gl/T4D2wH

53. Small ST, Tisch DJ, Zimmerman PA. Molecular epidemiology, phylogeny and evolution of the filarial nematode Wuchereria bancrofti. Infect Genet Evol. 2014; 28: 33-43. Ref.: https://goo.gl/5b4egv

54. Ramesh A, Small ST, Kloos ZA, Kazura JW, Nutman TB, et al. The complete mitochondrial genome sequence of the filarial nematode Wuchereria bancrofti from three geographic isolates provides evidence of complex demographic history. Mol Biochem Parasitol. 2012; 183: 32-41. Ref.: https://goo.gl/V5pJDX

55. Patra K, Ramu T, Hoti S, Pragasam GS, Das P. Identification of a molecular marker for genotyping human lymphatic filarial nematode parasite Wuchereria bancrofti. Exp Parasitol. 2007; 116: 59-65. Ref.: https://goo.gl/A8P2pt

56. Ghedin E, Wang S, Spiro D, Caler E, Zhao Q, et al. Draft genome of the filarial nematode parasite Brugia malayi. Science. 2007; 317: 1756-1760. Ref.: https://goo.gl/6rdRoo

57. Mitreva M, Blaxter ML, Bird DM, McCarter JP. Comparative genomics of nematodes. Trends Genet. 2005; 21: 573-581. Ref.: https://goo.gl/atxgDp

58. Blaxter M, Daub J, Guiliano D, Parkinson J, Whitton C, et al. The Brugia malayi genome project: expressed sequence tags and gene discovery. Trans R Soc Trop Med Hyg. 2002; 96: 7-17. Ref.: https://goo.gl/mr5oFS

59. McNulty SN, Mitreva M, Weil GJ, Fischer PU. Inter and intra-specific diversity of parasites that cause lymphatic filariasis. Infect Genet Evol. 2013; 14: 137-146. Ref.: https://goo.gl/fK2ntP 